\title{
"Espaço do povo": notas sobre o ethos discursivo do jornal comunitário de Paraisópolis
}

DOI: http://dx.doi.org/10.21165/el.v48i3.2336

\author{
Jaqueline Jurkovich ${ }^{1}$
}

\section{Resumo}

Neste artigo, a partir do aparato teórico-metodológico da Análise do Discurso de linha francesa, com ênfase nas reflexões de Dominique Maingueneau, analisamos o ethos discursivo do Espaço do Povo, jornal comunitário de Paraisópolis, a segunda maior favela da cidade de São Paulo. Do ponto de vista em questão, o ethos diz respeito à imagem que o enunciador projeta de si em seu discurso pelo modo como enuncia. Assim, não se trata exatamente do que o enunciador diz a respeito de si, mas das características psicológicas que projeta pelo modo de se exprimir. Desse modo, pelo ethos, tratamos de identificar, neste trabalho, a imagem do enunciador desse discurso e do universo em que ele se encontra, observando, para isso, certos indícios textuais de ordens diversas. A hipótese principal deste artigo é a de que a imagem de um jornal comunitário pode estar distante das imagens estereotipadas sobre a população carente e sobre a periferia das grandes cidades.

Palavras-chave: análise do discurso; jornalismo comunitário; ethos; Paraisópolis; Espaço do Povo.

1 Universidade Estadual Paulista "Júlio de Mesquita Filho" (UNESP), São José do Rio Preto, São Paulo, Brasil; jurkovich.jaque@gmail.com; https://orcid.org/0000-0001-5160-9842 


\title{
"Espaço do Povo": notes about the discursive ethos from a community newspaper in Paraisópolis
}

\begin{abstract}
In this article, based on the French line theoretical and methodological theories of Discourse Analysis, and focusing on Dominique Maingueneau's reflections, the discursive ethos from a community newspaper in Paraisópolis Espaço do Povo, the second largest slum of São Paulo city, will be analyzed. From this point of view, ethos is the speaker's image projected into his own discourse through the way he speaks. Thus, it's not only about what the speaker says per se, but also about his psychological characteristics projected in the way he speaks. Thereby, through ethos, we tried to identify the speaker's image from his discourse and context in which he is placed, observing various textual characteristics. So, the main hypothesis of this article is that the image of a community newspaper can be far from the stereotyped images about the needy population and the suburbs of big cities.
\end{abstract}

Keywords: discourse analysis; community newspaper; ethos; Paraisópolis; Espaço do Povo.

\section{Introdução}

Geralmente, nos jornais impressos de grande circulação do país, destinados ao público de uma cidade ou de um estado (jornalismo tradicional), a imagem das comunidades mais carentes dos grandes centros do Brasil - as chamadas "favelas" - costuma ser negativa. Assim, quando esses jornais relatam fatos que ocorreram dentro dessas comunidades, geralmente as notícias narram tragédias (desabamentos, incêndios) e/ou enfatizam violência (assassinatos, tiroteios) e tráfico de drogas. Subentende-se, dessa forma, que esses espaços urbanos são cenários de crimes e de péssimas condições de sobrevivência. Com isso, toda a complexidade que caracteriza qualquer tipo de ambiente humano é desprezada, o que não deixa de contribuir para que se tenha uma imagem negativa dos moradores dessas comunidades.

De fato, vários trabalhos de Psicologia Social, como os de Jost e Banaji (1994) e os de Fiske, Cuddy e Glick (2007), revelam que pessoas de classes mais baixas são frequentemente estereotipadas de forma negativa, consideradas ora como pessoas perigosas, ora como preguiçosas e acomodadas. Dessa forma, uma breve pesquisa pelas mídias tradicionais sobre notícias relacionadas às favelas já nos proporciona uma visão do modo como essa realidade é vista e reportada. A título de exemplo, foram retiradas notícias e imagens de alguns dos veículos digitais mais lidos no Brasil: 


\section{Incêndio destrói 50 casas em Paraisópolis, zona sul}

Morador tenta apagar fogo com balde de água; incêndio atingiu a favela de Paraisópolis

WERTHER SANTANA / ESTADAO

01 de Março de 2017| 16h23



Figura 1. Incêndio destrói 50 casas em Paraisópolis, zona sul -

Fonte: Estadão, março de 2017

SAOPAULO I $y \ldots$

Desabamento de 20 casas em Paraisópolis deixa dois feridos

SÃO PAULO - Cerca de 20 barracos desabaram na favela de Paraisópolis, na zona sul de São Paulo, no início da manhå deste domingo, 5 deixando duas pessoas feridas. $O$ acidente ocorreu por volta das 7 horas, após o desmoronamento de um pequeno morro na Rua Pasquale Gallupi, no meio

Fabio Leite e Luiz Fernando Toledo 05 de Junho de 2016 | $16 \mathrm{~h} 25$

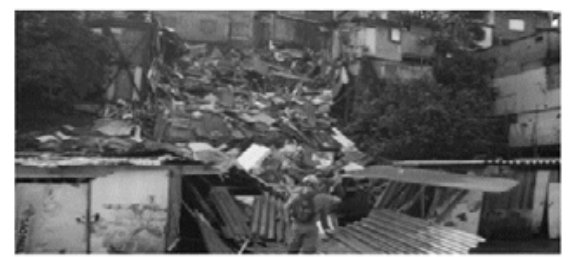

Figura 2. Desabamento de 20 casas em Paraisópolis deixa dois feridos

Fonte: Estadão, junho de 2016

\section{Polícia Militar realiza 'operação pancadão' em Paraisópolis}

SÃO PAULO - A poluiçăo sonora e o consumo de drogas estão entre as principais queixas de quem mora nas proximidades da Favela de Paraisópolis, na zona sul da cidade. Moradores da Fazenda Morumbi, bairro vizinho da comunidade,

reclamam do barulho em dias da semana. "Um dia

eu saíde casa

Renata Okumura

09 de Abril de 2018 | 12h18

Figura 3. Polícia Militar realiza "operação pancadão" em Paraisópolis Fonte: Estadão, abril de 2018 


\section{Brasil inseguro}

recente e revoltante foi o assassinato ainda não esclarecido da PM Juliane dos Santos Duarte, na favela de Paraisópolis. 0 fato de a Constituiçāo atribuir ao 19.ago. 2018 às 2 h00

Figura 4. Brasil inseguro

Fonte: Folha de S. Paulo, agosto de 2018

\section{Confronto na favela de Paraisópolis}

NOBLAT 12/09/2014 15h27

...Os moradores da favela Paraisópolis, a segunda maior de São Paulo, entraram em confronto com policiais militares hoje... levadas para o $89^{\circ}$ Distrito Policial (DP). A favela vai permanecer cercada pelos policiais, segundo a secretaria de Segurança Pública...

Figura 5. Confronto na favela de Paraisópolis

Fonte: O Globo, setembro de 2014

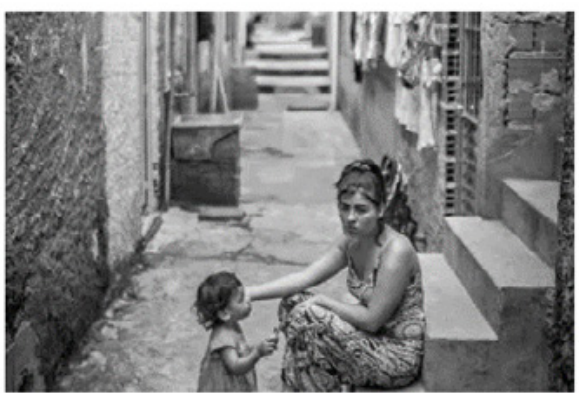

Revista VEJA

\section{Os efeitos da pobreza}

Q) 1 dez 2017,06h00

$f \succ G+\square$

Figura 6. Os efeitos da pobreza

Fonte: Revista Veja, dezembro de 2017

As notícias da figura 1 à figura 5 tratam deacontecimentos da favela (mais especificamente a de Paraisópolis) ligados a tragédias e a episódios de violência, abordando, por exemplo, casos de incêndio, de desabamento e de confrontos da polícia com os moradores. Já nas figuras 4 e 6, observa-se também como as expressões nominais empregadas para fazer referência direta ou indireta a essas comunidades (por exemplo, "Brasil inseguro" e "efeitos da pobreza") colaboraram para imprimir-lhes uma imagem negativa. Além disso, as fotografias presentes na maioria das notícias exibem cenas de perigo, medo e tristeza. 
O jornalismo tradicional, como se pode notar, costuma privilegiar uma forma específica de representar a realidade, promovendo a circulação de imagens negativas sobre certos grupos sociais e sobre suas condições de vida. Segundo Paiva (2006), esse tipo de jornalismo aborda os conteúdos de forma "espetacularizada", priorizando propósitos consumistas e tendenciosos e deixando de lado aspectos relevantes, como notícias que despertam a capacidade de interpretação e de pensamento crítico dos indivíduos. Por essa razão, de acordo com a autora, outro tipo de jornalismo emergiu, tendo como objetivo, para tanto, levantar pontos de vista mais condizentes com a realidade que reporta e com os indivíduos relacionados a ela. Dessa forma, Paiva (2006) menciona que se passou a considerar mais fortemente a voz dos grupos sociais, que muitas vezes não é mostrada, bem como a diferença na linguagem das notícias, que passam a ser abordadas de uma maneira menos tendenciosa.

\begin{abstract}
Desta maneira, pode-seacrescentar ainda, no intuito de mapeamento do jornalismo na atualidade, a ênfase excessiva na espetacularização, no baixo investimento do esforço cognitivo dos indivíduos, na frágil capacidade interpretativa da sociedade como um todo para com os fenômenos sociais, além do descarte dos processos contextualizatórios e historicizantes. É neste ambiente que se concebe como expressamente necessária a pesquisa e a experimentação em direção a um jornalismo relacional, interativo com a realidade atual e em benefício da agregação de valor humano à ordem social. (PAIVA, 2006, p. 63).
\end{abstract}

Esse novo conceito de jornalismo foi nomeado de jornalismo comunitário. Segundo Pena (2005) - levando em consideração, aqui, a perspectiva do jornalismo (e não da Análise do Discurso de linha francesa) - um jornal comunitário tem como foco dar voz à comunidade que representa, reivindicando mudanças, expondo problemas, relatando acontecimentos locais, informando sobre oportunidades (de emprego, estudo, atendimento médico, etc.) e, inclusive, mobilizando a união das pessoas que vivem na região. Além disso, de acordo com Pena (2005), um jornalista comunitário tem como foco enxergar os fatos com "os olhos da comunidade" e, por isso, atua de forma coerente na mediação das notícias. Desse modo, a afirmação de De Melo (2006, p. 126) complementa esse raciocínio: "[...] uma imprensa só pode ser considerada comunitária quando se estrutura e funciona como meio de comunicação autêntico de uma comunidade". Isso significa dizer: produzido pela e para a comunidade.

É importante ressaltar, aqui, que a intenção deste trabalho não é a de criar uma dicotomia entre mídia tradicional e mídia comunitária, visto que se trata de condições de produção e de objetivos muito distintos. Enquanto a mídia tradicional tem um público mais amplo e distinto e necessidades lucrativas, a mídia comunitária não precisa se preocupar tanto com isso, já que seu público é mais "selecionado" (as pessoas da comunidade em questão) e as necessidades lucrativas são bem menores e/ou inexistentes. 
Diante do exposto, neste trabalho pretende-se contribuir com os estudos que investigam as imagens relacionadas às comunidades por outro ponto de vista, isto é, o ponto de vista do próprio morador da periferia, a fim de dar visibilidade à voz dos grupos que sofrem preconceito e discriminação por conta desses estereótipos negativos que circulam a seu respeito. Para que seja cumprida essa meta mais ampla, pretende-se analisar o ethos do discurso do jornal Espaço do Povo, que é um jornal comunitário ligado à comunidade de Paraisópolis, de São Paulo. Trata-se de um jornal que existe há mais de dez anos, tendo se profissionalizado em 2013. Desde então, é veiculado mensalmente na comunidade e distribuído em todos os domicílios de forma gratuita. A opção por esse jornal se deve aos 10 anos que completou em 2017, o que evidencia que se trata de um jornal já consolidado, e à grande importância - e influência - que tem na região, com a distribuição gratuita de 20.000 exemplares por mês.

Quanto à opção pela análise do ethos, vale lembrar que, em linhas gerais, essa noção diz respeito à imagem que o enunciador projeta de si pelo modo como enuncia. Dessa forma, considerando que o enunciador do discurso em questão é um integrante de uma comunidade, com a análise proposta pretende-se apreender a(s) imagem(ns) que o jornal projeta do integrante de Paraisópolis (isto é, do próprio enunciador e também do público ao qual se dirige - moradores da região) e ainda a imagem da própria comunidade. Podemos, assim, dar visibilidade às vozes sociais que não têm espaço nos jornais tradicionais de grande circulação no país, o que deve contribuir para o combate aos preconceitos e à discriminação que recaem sobre comunidades de periferia.

\section{Sobre a noção de ethos discursivo}

O principal aparato teórico-metodológico que dará sustentação ao desenvolvimento deste trabalho é o da Análise do Discurso de linha francesa. Mais especificamente, entre as inúmeras dimensões da discursividade, seleciona-se para a investigação a relacionada ao ethos discursivo, na perspectiva de Dominique Maingueneau (2008). Segundo o autor, o ethos é a imagem que o enunciador projeta de si pelo modo como enuncia. De acordo com Maingueneau, o ethos não equivale ao que o enunciador diz sobre ele mesmo, mas, sim, ao que é revelado de suas características de personalidade pelo modo com que ele se expõe/se manifesta no discurso.

A noção de ethos emergiu da Retórica Antiga de Aristóteles e dizia respeito ao modo com que o locutor enunciava a fim de convencer seu auditório, tendo, para isso, intenções de persuasão. Porém, segundo Maingueneau (1989), do ponto de vista da Análise do Discurso de linha francesa, essa preocupação psicológica e voluntária deve ser abandonada, visto que, como o ethos é uma das dimensões do discurso, o enunciador não mais escolhe seu modo de enunciar em função dos efeitos que vai produzir, pois enuncia de acordo com o que é determinado por uma certa formação discursiva (doravante FD). 
Segundo Maingueneau (1989), o discurso não se separa de seu grupo social, ele não é dissociável do exterior que o compõe. É interessante ressaltar, inclusive, que o autor, em suas obras, pretende romper com o pensamento de que texto e contexto são coisas distintas, ou que um decorre do outro, sendo o texto constituinte da parte "interna" do discurso e o contexto da parte "externa". Isto é, para Maingueneau (1989), não há de um lado texto e de outro contexto, tudo é prática. Assim, Maingueneau (1989) afirma que o modo de enunciação de um discurso vai se constituindo de acordo com o posicionamento dos sujeitos e/ou das instituições que o compõem em uma determinada conjuntura e em um processo contínuo, já que o discurso é o produto de uma prática social.

A partir desse pensamento, Maingueneau (1989) esclarece que o ethos, como um componente de uma FD qualquer, é imposto por ela ao enunciador, afastando, assim, concepções que consideram o ethos voluntário. A esse respeito, o autor afirma que o ethos não diz respeito ao indivíduo real, mas, sim, ao indivíduo enquanto sujeito enunciador, isto é, ao enunciador que "se mostra" ao seu interlocutor por meio de uma maneira de enunciar. Sendo assim, essa maneira de enunciar é regida pelos processos socio-históricos que constituem uma determinada FD. Dessa forma, a partir do ethos do enunciador, o interlocutor é capaz de formar uma representação do sujeito da enunciação, que passa a executar o papel de "fiador" do discurso. Nas palavras do autor:

Todo texto escrito, mesmo que o negue, tem uma 'vocalidade' que pode se manifestar numa multiplicidade de 'tons', estando eles, por sua vez, associados a uma caracterização do corpo do enunciador (e, bem entendido, não do corpo do locutor extradiscursivo), a um 'fiador', construído pelo destinatário a partir de índices liberados na enunciação. (MAINGUENEAU, 2008, p. 17-18).

De acordo com Maingueneau (1995), essa vocalidade do discurso se manifesta não apenas no modo oral, mas também no escrito. A esse respeito, Maingueneau entende que o escrito não deve ser tomado como uma oralidade enfraquecida ou como um objeto tido a partir da oralidade. Isso quer dizer que, mesmo se tratando de texto escrito, sempre há uma voz específica que habita a enunciação. O autor nomeia essa voz de "tom", fazendo uma analogia entre o "tom" de uma pessoa e de um texto. Dessa forma, para o autor "o que é dito e o tom com que é dito são igualmente importantes e inseparáveis" (MAINGUENEAU, 1989, p. 46), sem hierarquia entre o que se diz e o modo com que se diz. Esse tom, entendido como um ideal de enunciação que acompanha os lugares de enunciação, está relacionado a um caráter e a uma corporalidade. O caráter

[...] corresponde a este conjunto de traços "psicológicos" que o leitor-ouvinte atribui espontaneamente à figura do enunciador, em função de seu modo de dizer. [...] Bem entendido, não se trata aqui de caracterologia, mas de estereótipos que circulam em uma cultura determinada. Deve-se dizer o mesmo a propósito da "corporalidade", que remete a uma representação do corpo do enunciado da 
formação discursiva. Corpo que não é oferecido ao olhar, que não é uma presença plena, mas uma espécie de fantasma induzido pelo destinatário como correlato de sua leitura. (MAINGUENEAU, 1995, p. 47).

A corporalidade remete, portanto, a uma representação do corpo do enunciador, isto é, o fiador do discurso, o que pode englobar tanto uma certa constituição corporal quanto uma certa forma de se vestir e de se mover no espaço social. Nesse sentido, o ethos é uma maneira de dizer relacionada a uma maneira global de ser, a um modo específico de habitar o mundo (cf. MAINGUENEAU, 1989-2006). Com isso, o destinatário, por meio do modo de enunciação, isto é, por meio do ethos, consegue apreender, graças a indícios textuais diversificados, uma certa representação do fiador do discurso.

Considerando, então, a constituição do ethos por meio das posições que os sujeitos ocupam ao enunciar, em uma dada formação discursiva - pelas relações (contraditórias) que suas palavras estabelecem com outras - Maingueneau (2001, p. 43) trata da cena de enunciação, deixando claro que "um texto não é um conjunto de signos inertes, mas o rastro deixado por um discurso em que a fala é encenada.". Segundo o autor, a "cena de enunciação" integra, na verdade, três cenas a que propõe nomear de cena englobante, cena genérica e cenografia. A cena englobante está relacionada com o estatuto pragmático do discurso (literatura, publicidade, religião, filosofia, etc.). A cena genérica corresponde ao gênero discursivo (carta, receita, editorial, sermão, etc.). E, por sua vez, a cenografia consiste no espaço em que o fiador do discurso se encontra, construindo, assim, o modo de enunciação.

Tendo como base a noção de ethos pela perspectiva de Maingueneau (2006, p. 271), é possível perceber como "é insuficiente ver a instância subjetiva que se manifesta por meio do discurso apenas como estatuto ou papel. Ela se manifesta também como uma 'voz' e, além disso, como 'corpo enunciante', historicamente especificado e inscrito em uma situação, que sua enunciação ao mesmo tempo pressupõe e valida progressivamente". No caso, esse corpo enunciante faz referência às diferentes representações que circulam numa certa sociedade, ou seja, os estereótipos. Além disso, segundo Maingueneau, o público pode construir representações prévias do enunciador antes mesmo que ele enuncie, pois há certos tipos de discursos que induzem expectativas em matéria de ethos.

Portanto, Maingueneau, com base nas reflexões que desenvolve sobre o tema, diferencia os seguintes tipos de ethé: (i) o ethos pré-discursivo, que diz respeito às representações prévias do ethos do enunciador que o destinatário dispõe em função do tipo/gênero do discurso ou do seu posicionamento ideológico; e (ii) o ethos discursivo, que corresponde ao ethos dito e ao ethos mostrado. $\mathrm{O}$ ethos dito faz referência ao próprio enunciador, enquanto o ethos mostrado está no âmbito do não implícito, ou seja, da imagem que é construída pelo interlocutor por meio das pistas que o enunciador oferece no discurso. Maingueneau (2006, p. 270) afırma também que "o ethos efetivo, aquele que é construído por um dado 
destinatário, resulta da interação dessas diversas instâncias, cujo peso respectivo varia de acordo com os gêneros do discurso.

Por fim, cumpre observar que, como os funcionamentos discursivos não são definidos a priori do discurso, a análise do ethos se desenvolve a partir de alguns indícios textuais que se revelaram pertinentes para a identificação dos tons do discurso, a saber: temas tratados, léxico e modo de interpelação do enunciatários.

\section{Jornalismo comunitário e ethos pré-discursivo}

O corpus desta pesquisa, como já mencionado, é composto por edições impressas do jornal comunitário Espaço do Povo, veiculado em Paraisópolis, na cidade de São Paulo. Os primeiros passos do Espaço do Povo foram dados graças ao grêmio estudantil chamado Espaço Jovem, que iniciou inúmeros projetos sociais, dentre os quais estava a ideia de criar um jornal comunitário. Em 2003, Joildo Santos, popularmente conhecido como Santos, criou um jornal que abordava os fatos que aconteciam na comunidade. Essa primeira versão do jornal era, de certa forma, amadora e ainda não contava com tanta adesão do público. Com o tempo, o jornal foi ganhando importância e visibilidade e, em abril de 2007, recebeu o nome atual (Espaço do Povo), com a idealização de Santos e com o auxílio de sua equipe.

A sede do Espaço do Povo se localiza na "União dos Moradores e do Comércio de Paraisópolis", que atua como uma prefeitura local, responsável por gerir e levar aos órgãos públicos os principais problemas encontrados na região. Graças ao apoio dessa prefeitura local, o Espaço do Povo se profissionalizou em 2013 e completou dez anos em 2017. Desde então, o jornal é formado por uma equipe de, em média, seis pessoas e produz mensalmente 20.000 exemplares, que são distribuídos de forma gratuita nos 17.000 domicílios da comunidade.

Segundo Joildo Santos, o conteúdo do jornal conta com a participação ativa das pessoas da comunidade, prezando pelas sugestões e pela "voz" dessas pessoas. Além disso, Santos considera que nenhuma notícia é publicada aleatoriamente; ele afirma que a temática abordada em seu jornal tem o objetivo de "promover uma ação", de chamar a atenção das pessoas (e até mesmo do governo) para agir. O diretor afırma que a divulgação dos eventos e dos projetos ajuda a contemplar o crescimento humano daquela região e o debate e a participação dos leitores por meio de comentários nas redes sociais do jornal - outra maneira de dar "voz" à comunidade.

Essas afirmações de Santos nos ajudam a formar expectativas em termos do ethos discursivo no discurso do jornal em questão e em relação às nossas hipóteses de pesquisa. Como o ethos pré-discursivo tem relação com o tipo/gênero do discurso, a primeira e principal hipótese que sustenta este trabalho é a de que o ethos de um jornal 
comunitário difere do ethos de um jornal tradicional (que circula todos os dias em uma determinada cidade ou estado, por exemplo) e que as imagens das comunidades carentes são distintas nesses dois tipos de discurso jornalístico. A esse respeito, vale lembrar que

A grande mídia chega para todo mundo, mas ela não tem a mobilidade de chegar falando a linguagem local, ela não sabe o nome das pessoas, ela não conhece os costumes. Ela apenas faz um recorte da realidade, mas não dá conta de passar toda a realidade com sua cor local. Só o comunitário pode fazer isso, porque está inserido fortemente na comunidade. (CAMPOS, 2006, p. 1).

A segunda hipótese, ligada à primeira, diz respeito à expectativa de que o discurso do jornal seja marcado por um tom didático e por um tom de proximidade com o leitor, tanto pela escolha do conteúdo de suas notícias quanto pela linguagem, dadas as finalidades desse tipo de discurso jornalístico. A esse respeito, Paiva (2003, p. 139) observa:

Uma caracterização importante é o acentuado uso didático, diferindo bastante da concepção usual que se tem de notícia, por exemplo. O destaque aos assuntos é dado em função da sua importância para o grupo social, numa relação direta com o cotidiano das pessoas.

Essas mesmas expectativas ganham reforço nas considerações feitas por Campos (2006) a respeito do jornalismo comunitário. De acordo com o autor, uma das características que diferencia o jornalismo comunitário do jornalismo tradicional, além do intuito e dos temas abordados, é justamente a linguagem. O autor afirma que, por se tratar de uma mídia feita pela e para a comunidade, não se costuma empregar palavras rebuscadas e não se apresenta tanta preocupação com formalidades. Pelo contrário, é muito comum que se observe em jornais comunitários uma linguagem leve, direta, informal e didática, destinada a dialogar com o público como um locutor que vive a mesma realidade e sabe reportá-la da forma que realmente é (isto é, a realidade, de forma geral, de quem vive na comunidade, não excluindo as diferentes ideologias dos sujeitos), além de tentar garantir espaço e voz para todos os envolvidos. Nas palavras do autor:

A proximidade entre as pessoas é a principal característica do meio comunitário. As pessoas se conhecem e se reconhecem (como dizia Paulo Freire) nos seus problemas, angústias, alegrias e ritos cotidianos. Essa reconhecibilidade também exige uma linguagem referenciada aos costumes do grupo social. É uma linguagem coloquial, de fácil entendimento, reconhecível em suas gírias e modismos. Hoje, ou em qualquer época, jornalismo comunitário é uma atividade de comunicação originada na comunidade, administrada pela comunidade e dirigida à comunidade. (CAMPOS, 2006, p. 1). 


\section{0 ethos mostrado}

Conforme já dito, a análise do ethos mostrado está centrada em três aspectos de natureza linguístico-discursiva: léxico, temas tratados e formas de interpelação do destinatário. Quanto ao léxico, observa-se o emprego de palavras e de expressões informais, próprias de uma linguagem que produz efeito de proximidade com o leitor e típica de situações informais e de fala cotidiana. Vejam-se alguns exemplos:

(1) A comunidade não ficou de fora [...] (EP, março/abril de 2010, p. 2)

(2) De pertinho eu enxergo que é uma beleza, agora de longe... xiiii" (EP, Especial 2016, p. 14)

No exemplo (1), pode-se observar a expressão informal "ficou de fora", típica da linguagem falada e/ou de uma conversa informal, do mesmo modo que acontece no exemplo (2) com a expressão "que é uma beleza". Também pode-se observar no exemplo (2) o uso do diminutivo "pertinho" que, neste contexto, pode ser entendido como uma atenuação da palavra "perto", o que confere ao discurso um tom de afetividade. Além disso, no exemplo (2), há o emprego da interjeição "xiiii", o que mostra, claramente, a presença de marcas informais no léxico do enunciador, assim como marcas de oralidade e de interação. Vejamos o próximo exemplo:

(3) Olá, people! Como fui uma menina má na última edição e não passei a receita do fondue de chocolate, revolvi passar duas receitas quentinhas e deliciosas para aquecer os corações. Beijo no $\underline{\text { ! }}$ (EP, julho/agosto 2016, p. 13)

Neste exemplo, também é possível observar marcas informais no léxico, além de marcas de oralidade e de interação, como em: "Olá, people!", com a saudação "olá" e o vocativo em inglês "people" (pessoas); em "passar", com o verbo utilizado com uma implicação próxima da comunicação cotidiana; e em "quentinhas", com o emprego do diminutivo, o que confere ao enunciado, no contexto em questão, um tom de afetividade. Conjuntamente, em (3), há a expressão "aquecer os corações", uma expressão "clichê", que geralmente é percebida em contextos de fala, e a presença do símbolo de um coração, comum em contextos informais de comunicação digital. Neste exemplo, o modo com que o enunciador se expressa revela que se trata de um sujeito inserido em uma situação de informalidade, próximo ao interlocutor. Além disso, o emprego de um vocativo em inglês e de um símbolo da linguagem digital (o coração) projeta a imagem de uma pessoa "ligada no mundo" e às suas tendências atuais.

Quanto aos temas tratados, pode-se observar, no Espaço do Povo, matérias que versam sobre assuntos relacionados com a comunidade, como ocorre em: 




Figura 7. Craques do Amanhã

Fonte: EP, Especial 2016, p. 6

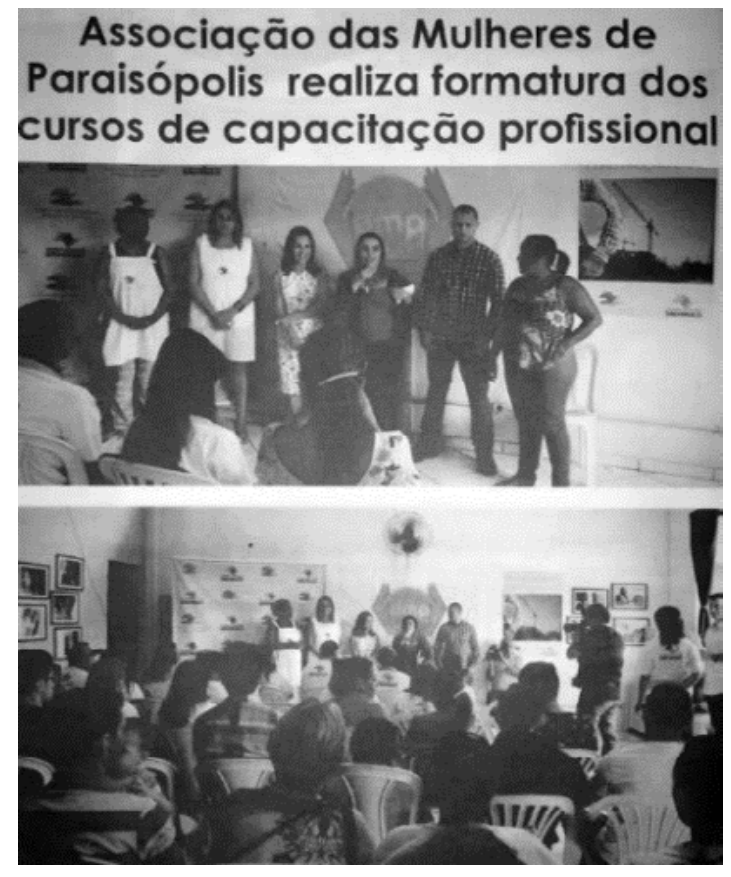

Figura 8. Associação das Mulheres de Paraisópolis

Fonte: EP, Especial 2016, p. 12 


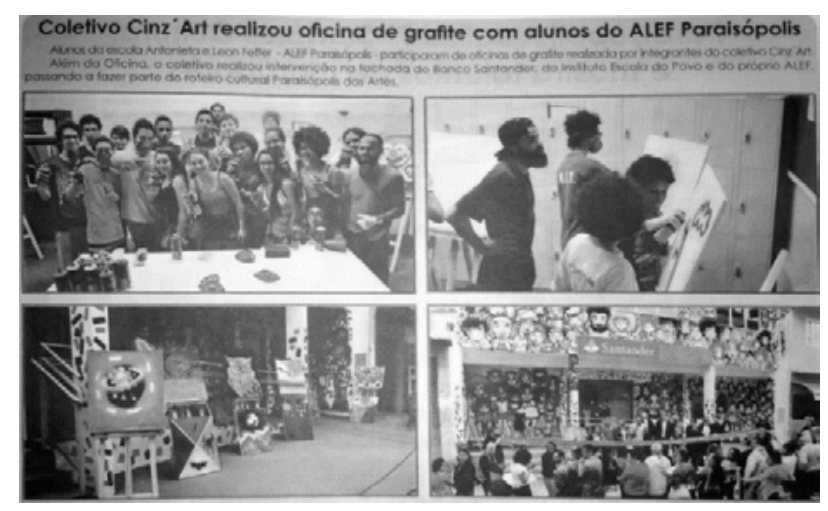

Figura 9. Coletivo Cinz' Art

Fonte: $E P$, Especial 2016, p. 4

Como se pode notar, as matérias em questão relatam eventos realizados em benefício da comunidade: recreação esportiva promovida por professores para as crianças da comunidade, formatura de um curso de capacitação para mulheres, realização de uma oficina de grafite para alunos de uma escola de Paraisópolis. Essas matérias estão acompanhadas por fotografias que exibem cenas validadas ${ }^{2}$, nos termos de Maingueneau (2006), relativas à vida em comunidade, a saber: cenas de crianças brincando/praticando esportes em conjunto, de adultos trabalhando lado a lado na realização de projetos comunitários e de jovens participando de atividades culturais.

A partir disso, é possível perceber que esses projetos sociais, encenados nas figuras, focalizam esportes, educação e lazer e promovem também uma outra imagem do morador e do ambiente da favela, bem diferente da reportada frequentemente pela mídia tradicional. No caso, a mídia tradicional retrata o ambiente da região periférica como perigoso e hostil e o morador como criminoso, violento ou vítima da pobreza e da violência, enquanto a mídia comunitária, no caso, o jornal Espaço do Povo, retrata o bairro como um ambiente onde se realizam diversas práticas (tais como, esporte, cultura e atividades de formação) promovidas em prol da comunidade. O morador, por sua vez, é retratado como alguém engajado, participativo e integrado à sua comunidade, ou seja, não é agente nem vítima da violência, tal como costuma ser retratado em outros discursos.

Em relação às formas de interpelação do enunciatário, pode-se notar, na linguagem do jornal em questão, uma comunicação direta do enunciador com seus enunciatários, o que demonstra, ainda mais, um efeito de proximidade entre quem lê e quem escreve, como observa-se em:

2 Cenas validadas, segundo Maingueneau (2008), dizem respeito às cenas que já estão instauradas na memória coletiva e que podem, dessa forma, ser aprovadas ou rejeitadas. 
(4) Você sabia que fazer acusações sem provas pode levar a processo judicial?

(EP, julho/agosto, 2016, p. 12)

(5) Da última vez que você comprou alguma coisa, o que foi? (EP, julho/agosto 2016, p. 4)

(6) Nossa união lutando por Paraisópolis em todos os lugares. (EP, março/abril de 2010, p. 4)

(7) Fruto de uma nova etapa que vivemos, nossa rádio comunitária levará em seu nome o reflexo das mudanças que norteiam a nossa realidade. (EP, março/abril de 2010, p. 3)

Nos exemplos (4) e (5), há o uso do pronome "você", interpelando diretamente o enunciatário, como se fosse em um diálogo, além das formas interrogativas das sentenças, o que caracteriza, ainda mais, um contexto de interação entre enunciador e enunciatário. Já nos exemplos (6) e (7), o emprego de formas da primeira pessoa do plural, como "nossa", "vivemos", também demonstra um efeito de interação e interpelação, mesmo que de uma maneira menos direta do que os exemplos (4) e (5). Isso porque o emprego de formas de primeira pessoa do plural ("nossa"; "vivemos") é "a junção de um eu com um não-eu" (FIORIN, 1996, p. 60), ou seja, não caracteriza só o enunciador falando do seu lugar de enunciação para o seu enunciatário, mas, sim, a fala do locutor se unindo à do enunciatário, como se ambos se dispusessem da mesma vivência e da mesma realidade. "O nós inclui o enunciatário no enunciador e, portanto, aquele é obrigado por este a assumir o texto com ele." (MAINGUENEAU, 1981 apud FIORIN, 1996, p. 91).

(8) Você, morador de Paraisópolis, aluno do $9^{\circ}$. Ano/8a. Série, venha participar do processo seletivo para fazer parte do ensino médio da Associação Crescer Sempre! (EP, setembro, 2013, p. 9)

Em (8), há o aparecimento do pronome "você", interpelando o enunciatário, e dos vocativos "morador de Paraisópolis" e "aluno do $9^{\circ}$ Ano/8a Série". Além disso, o verbo imperativo "venha" também é responsável por essa interpelação, chamando, de forma direta, o enunciatário para agir. Dessa maneira, os modos de enunciar produzem um efeito de conhecimento sobre o seu enunciatário que, no caso de (8), além de ser um morador de Paraisópolis, é um aluno do $9^{\circ}$ ano. Com isso, pode-se perceber o efeito de proximidade entre ambos pelo modo de tratamento direto e pelo uso do vocativo, que revela que o enunciador tem um alvo específico.

A partir dessa análise prévia e das noções sobre ethos discursivo, de Maingueneau, já explicitadas no item 1, pode-se dizer que o ethos do Espaço do Povo apresenta um 
tom informal e de proximidade, confirmando as hipóteses inicialmente formuladas em termos de ethos pré-discursivo. Com isso, também é possível salientar a diferença entre a linguagem de um jornal comunitário e a de um jornal tradicional, que dificilmente apresentaria os aspectos mencionados nos exemplos acima. Dessa forma, um jornal tradicional teria, então, tons distintos e, consequentemente, um ethos distinto de um jornal comunitário. Ademais, do ponto de vista adotado neste trabalho, todos os aspectos citados corroboram para a sustentação de outro tom no discurso do Espaço do Povo: o tom didático.

De fato, o tom didático está evidente em todo o jornal, especialmente em matérias escritas por especialistas de fora da comunidade. Os temas dessas matérias dizem respeito a assuntos bastante diversificados e de interesse geral, não apenas das pessoas da comunidade, tais como, direitos do consumidor, questões de saúde e alimentação, novas leis, novidades do mundo digital, atividades domésticas etc. Desse ponto de vista, o jornal projeta a imagem do morador de Paraisópolis como a de uma "pessoa do mundo", com interesses, necessidades e práticas iguais aos de qualquer pessoa que vive numa sociedade como a atual. A seguir, apresentam-se algumas matérias desse tipo:

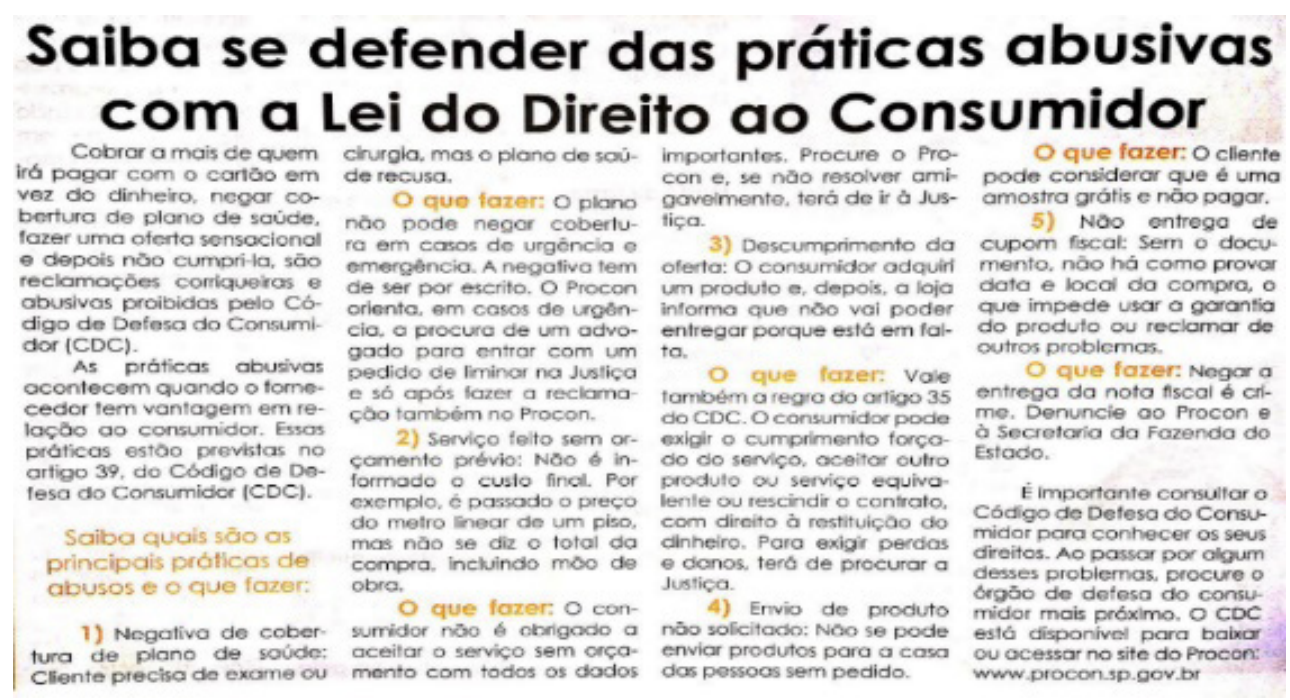

Figura 10. Saiba se defender das práticas abusivas com a Lei do Direito ao Consumidor

Fonte: EP, julho/agosto, 2016, p. 14 


\section{Fofocas, calúnias e difamação podem levar a processo judicial}

\begin{tabular}{|c|c|c|c|}
\hline  & $\begin{array}{l}\text { Difamação } \\
\text { - o que é? É im- } \\
\text { putar um fato que } \\
\text { não é crime, mas que } \\
\text { ofende a reputaçăo. } \\
\text { na presença de tercei- } \\
\text { ros ou que chegue a } \\
\text { conhecimento de ter- } \\
\text { ceiros. Exemplo: dizer } \\
\text { que um empregador } \\
\text { protege tal funcioná- } \\
\text { rio em detrimento de } \\
\text { outros é difamação, já } \\
\text { que isso năo é crime. } \\
\text { - Pena: Detenção } \\
\text { de três meses a um } \\
\text { ano, e multa. } \\
\text { Ou seja, para ha- } \\
\text { ver crime de difama- } \\
\text { ção elou calúnia são } \\
\text { necessárias apenas as apenas }\end{array}$ & $\begin{array}{l}\text { sor, o agredido e um } \\
\text { terceiro. Também é } \\
\text { importante saber que } \\
\text { é possível ser conde- } \\
\text { nado por esses crimes } \\
\text { apenas por propagá- } \\
\text { los. Não é necessário } \\
\text { ser quem inventou a } \\
\text { mentira para ser pro- } \\
\text { cessado. } \\
\text { portanto, deve-se } \\
\text { tomar muito cuidado } \\
\text { com comentários fei- } \\
\text { tos em público sobre } \\
\text { determinada pessoa } \\
\text { e seus atos, princi- } \\
\text { palmente em assem- } \\
\text { bleias, já que em al- } \\
\text { guns casos, os annimos } \\
\text { podem se exaltar e é } \\
\text { possivel que escape } \\
\text { algum comentário in- } \\
\text { desejável, que não } \\
\text { esteja em consoante } \\
\text { com a verdade. } \\
\text { Porém, qualquer } \\
\text { conversa em que se } \\
\text { atribua a outra pessoa }\end{array}$ & $\begin{array}{l}\text { ou nāo fez, e se en- } \\
\text { quadra na descrição } \\
\text { acima, já pode ser } \\
\text { considerada difama- } \\
\text { tória ou caluniosa. } \\
\text { Deve-se empre- } \\
\text { gar cuidado especial } \\
\text { em situaçōes conside- } \\
\text { radas adversas, como } \\
\text { brigas, reclamaçōes } \\
\text { devido a barulho ex- } \\
\text { cessivo. desentendi- } \\
\text { mento com funcio- } \\
\text { nários, entre outros. É } \\
\text { nas horas da cabeça } \\
\text { quente que pode vir } \\
\text { a tona uma palavra } \\
\text { indevida. } \\
\text { Portanto, antes } \\
\text { de sair destilando sua } \\
\text { raiva contra alguém. } \\
\text { fazendo queixas ou } \\
\text { acusações sem funda- } \\
\text { mento, respire fundo } e \\
\text { exponha o problema } \\
\text { sem ofensas. Pois, as- } \\
\text { sim, irá evitar grandes } \\
\text { problemas judiciais. }\end{array}$ \\
\hline
\end{tabular}

Figura 11. Fofocas, calúnias e difamação podem levar a processo judicial

Fonte: $E P$, julho/agosto, 2016, p. 12



Figura 12. Veja algumas dicas para tirar o cheiro da roupa

Fonte: $E P$, julho/agosto, 2016, p. 15 
Na figura 10, há uma matéria que trata de práticas abusivas relacionadas à Lei do Direito ao Consumidor e que explica ao leitor como ele pode se defender e lutar pelos seus direitos. O tom didático da matéria pode ser percebido pela numeração de itens, pelo emprego da expressão "o que fazer" seguida de dois pontos, precedendo um esclarecimento. Além disso, há destaque de cor amarela para os pontos a serem considerados mais importantes para o leitor. Na figura 11, também há uma matéria que procura explicar como fofocas, calúnias e difamação podem levar a processo judicial, com perguntas e respostas - "o que é?", e destaques em negrito para as nomenclaturas e para as perguntas, precedendo a explicação. Já na figura 12, é possível perceber uma matéria que apresenta imagens (isto é, linguagem não-verbal) de roupas precedendo a explicação, juntamente com os nomes dos tipos de tecido destacados em negrito e seguidos por dois pontos.

Dessa forma, nessas matérias extraídas, relativas ao tom didático, é possível notar uma linguagem direta, com foco nas explicações, com apresentações esquemáticas (do tipo passo a passo, pergunta e resposta) e com elementos de linguagem não-verbal acompanhando a linguagem verbal. Com isso, fica evidente a prévia confirmação da segunda hipótese deste trabalho, que formula expectativas de que o discurso em questão seja marcado por um tom didático e por um tom de proximidade com o leitor.

\section{Considerações finais}

Os primeiros resultados da análise, que ainda se encontra num estágio bastante inicial, revelam que, no jornal comunitário que constitui o corpus, predominam dois tons em termos de ethos discursivo. Nas matérias atribuídas aos redatores do jornal ou às pessoas da própria comunidade, matérias que versam sobre os acontecimentos e oportunidades da região, há um tom mais informal, próprio de um enunciador que se projeta como alguém próximo a seu enunciatário inserido no mesmo mundo ético. Além disso, há um tom entusiasmado de incentivo social, voltado ao bem-estar e desenvolvimento da comunidade. Por outro lado, nas matérias atribuídas a profissionais especializados, pessoas de fora da comunidade, matérias que tratam de temas diversos (saúde, alimentação, sexualidade, educação etc.) há um tom didático muito evidente, próprio do discurso de divulgação científica, em que um especialista dialoga com um público leigo.

Portanto, pode-se dizer que o enunciador do Espaço do Povo, é um integrante da comunidade, alguém que produz um efeito próximo de seu enunciatário, além de ser uma pessoa engajada com os temas e assuntos de interesse da comunidade. Do mesmo modo, o enunciatário é um morador da comunidade, interessado em assuntos variados, tais como: ofertas de emprego, cursos, aperfeiçoamento profissional, eventos culturais, eventos esportivos, dicas domésticas, cuidados com saúde e com a alimentação, etc. E, por fim, a vida cotidiana de Paraisópolis não se limita às práticas de violência e carência/ precariedade geralmente atribuídas a ela, apresentando promoção de esporte, lazer, educação e cultura. 


\section{REFERÊNCIAS}

AMOSSY, R.; PIERROT, A. H. Estereotipos y clichés. Buenos Aires: Eudeba, 2001.

CAMPOS, P. C. Professor do curso de Jornalismo da Universidade Estadual Paulista (UNESP/Bauru). Entrevista aos autores. 20/09/2006. Por e-mail.

DE MELO, J. M. Teoria do Jornalismo - identidades brasileiras. São Paulo: Paulus, 2006.

FIORIN, J. L. As Astúcias da Enunciação: as categorias de pessoa, espaço e tempo. São Paulo: Ática, 1996.

FISKE, S. T.; CUDDY, A. J. C.; GLICK, P. Universal dimensions of social perception: warmth and competence. Trends in Cognitive Science, v. 11, n. 2, p. 77-83, 2007.

JOST, J. T.; BANAJI, M. R. The role of stereotyping in system-justification and the production of false consciousness. British Journal of Social Psychology, v. 33, p. 1-27, 1994.

MAINGUENEAU, D. Problemas de ethos. In: POSSENTI, S.; SOUZA-E-SILVA, M. C. P. de (org.). Cenas da enunciação. São Paulo: Parábola Editorial, 2008. p. 55-73.

MAINGUENEAU, D. Discurso literário. São Paulo: Contexto, 2006.

MAINGUENEAU, D. Gênese dos discursos. Curitiba: Criar Edições, 2005.

MAINGUENEAU, D. Análise de textos de comunicação. São Paulo: Cortez, 2001.

MAINGUENEAU, D. Novas tendências em Análise do Discurso. Campinas: Fontes \& Editora da UNICAMP, 1989.

PENA, F. Teoria do Jornalismo. São Paulo: Contexto, 2005.

PEREIRA, M. E. et al. Imagens e significado e o processamento dos estereótipos. Estudos de Psicologia, v. 7, n. 2, p. 389-397, 2002.

PAIVA, R. Jornalismo comunitário: uma reinterpretação da mídia (pela construção de um jornalismo pragmático e não dogmático). FAMECOS: mídia, cultura e tecnologia, Porto Alegre, v. 1, n. 30, p. 62-70, 2006. DOl:http://dx.doi.org/10.15448/1980-3729.2006.30.3376 
PAIVA, R. O espirito comum - Comunidade, mídia e globalismo. Rio de Janeiro: Mauad, 2003.

SOUZA-E-SILVA, M. C. P.; BRAIT, B. (org.). Texto ou discurso? São Paulo: Contexto, 2012. 